Pontifical Academy of Theology

Cracow

\author{
Joseph Życiński \\ HOW TO DE-RUSE SOCIOBIOLOGICAL THEORY \\ OF KNOWLEDGE?
}

\title{
SCIENCE IN EVOLUTIONARY PERSPECTIVE
}

The epistemological significance of E. O. Wilson's sociobiology has been enthusiastically proclaimed by Michael Ruse in his version of the so-called Darwinian epistemology. When trying to develop its tenets, Ruse argues that the principle of the survival of the fittest should be consistently applied not only to the domain of biological organisms but also to scientific theories and their competition in the struggle for survival. This claim seems scarcely original since in authors like Herbert Spencer, Ernst Mach, and Karl Popper we find its anticipations in various metaphors that describe the growth of scientific theories in biological terms related to natural selection. Ruse's declarations seem, however, much stronger than the suggestions mentioned above when he claims that „there are very good biological reasons" to regard mathematical theorems as objective truths because the theorems at stake give us ,a selective advantage" in the struggle for survival ${ }^{1 .}$ Such a statement must not result in the rejection of epistemological realism or imply an irrationalist stance in the theory of knowledge. Ruse explicitly declares that as a former logical empiricist he was and still is , attracted to the rationality of science”, and still asserts that ,the course of science is ... not totally without sane reason" 2 .

\footnotetext{
$1 \quad$ M. Ruse, Taking Darwin Seriously?: A Naturalistic Approach to Philosophy, Basil Blackwell: 1986, 172. In the subsequent notes this book is denoted by the symbol TD.

2 M. Ruse, Introduction, [in:] Nature Animated, ed. M, Ruse, D. Reidel: Dordrecht 1983, 10.
} 
In this paper I try to answer what precisely is meant by the mysterious „attraction", and how can a critical version of sociobiological epistemology be reconciled with the standpoint of metascientific rationalism. My answer to the latter question is that sociobiology and rationalism can be reconciled only if one rejects, or substantially modifies, those statements in Ruse's expositions that seem much closer to rhetoric than to critical metascientific reflection.

\section{ARE SCIENTIFIC THEORIES ADVANTAGE-LADEN?}

When developing his version of a sociobiological theory of knowledge, Ruse presents it as a natural consequence of the Darwinian approach and argues that ,a century and a quarter after the appearance of On the Origin of Species, the time has surely come to take Darwin seriously" ${ }^{3}$. This very statement suggests that for 125 years Darwin was not treated seriously, and that to be a serious Darwinist one must introduce to the theory of knowledge the strong assumptions accepted by $\mathrm{E}$. O. Wilson in his radical version of sociobiology ${ }^{4}$. The question arises, however, whether at the same time in evolutionary epistemology one can treat seriously the rational heritage of mankind and its particular role in our culture.

To answer this question we must assess two substantial assumptions in the sociobiological theory of knowledge. They assert respectively that:

1. The content of scientific theories is biology-laden as well as genetically conditioned.

2. In the growth of human knowledge, the victorious are those theories that give to the human species evolutionary advantages in the struggle for survival.

These vague statements could imply essentially different epistemological stances depending on the meaning ascribed to such terms as „conditioned”, „victory”, „advantage”. There is nothing per se controversial in Ruse's arguments when he claims that „scientific methodology is grounded in epigenetic rules, brought into existence by natural selection" 5 . To determine the exact content of such statements one has to define, however, the precise meaning of the expression ,grounded in" and its metaphorical counterparts that are abundantly used by Ruse.

It is hard to determine a clear meaning when Ruse aphoristically ascertains that our knowledge is „biologically based” on these rules, and that epigenetic rules ,influence our thought". Depending on what meaning we ascribe to the terms "grounded", „based”, „constrains”, „influences”, we may obtain either a trivial or evidently irrational theory of knowledge.

${ }^{3} \mathrm{TD}, 279$.

${ }^{4}$ I use the expression „radical sociobiology" to denote the version proposed by Wilson in On Human Nature and developed in his works in the 1970's. The term ,,moderate sociobiology” denotes sociobiological theories developed by Burhoe, Barash and the authors who focus upon biological issues and reduce to a minimum ideological extra-scientific comments.

5 TD, 279.

${ }^{6} \mathrm{TD}, 170$. 
Nobody would question Ruse's statement that ,the proto-human who innately preferred ' $2+2=4$ ' to ' $2-1-2=5$ ' was at a selective advantage over his/her less discriminating cousin" " . Nonetheless, in another text the same notion of the „selective advantage" dependent on knowledge seems semantically less clear, when, for instance, Ruse contends that ,the human who instinctively recognizes and prefers sweet things to sour or rotten things is at a clear advantage to the human whose palate is indifferent to tastes" ${ }^{8}$. This contention seems at least controversial since one might argue as well that human indifference to palate pleasures would facilitate our struggle for survival because it makes us indifferent to and independent of the quality of the food available.

The semantic fuzziness of the basic notion of the „selective advantage" is well illustrated by A. Zahavi's paradoxical conception of the selective advantage of having a handicap 9 . In this approach, a handicapped animal could increase his genetic successes if he attracts females by the very fact that in spite of his biological disadvantages, he is able to participate in the struggle for survival. In such an interpretative approach, dialectic is mixed with rhetoric; disadvantage means advantage, and any conclusion can be deduced from the set of ambiguous elementary assumptions.

Setting aside the discussions on the precise meaning of the basic concepts that are used in sociobiological epistemology, we may direct our attention to those simple cases that are evidently noncontroversial. An example is the thesis of the biological basis of human knowledge. Except for eccentric defenders of the theory of the tabula rasa, nobody would question either that our biology in a sense ,influences” and "constrains" our mathematics or that, in the accordance with the famous phrase of Wilson, the content of scientific theories also is, in a sense, „held on a leash" by genes. If we had the brain of a macaque, we certainly could not develop the black hole physics and the quaternion calculus. The most important question remains, however, how long is the genetic leash, and how strong is its impact on the content of scientific knowledge.

In his many statements Ruse definitely rejects the trivial interpretation of his naturalized epistemology. He consistently accentuates the novel character of the Wilsonian approach and expresses his disappointment with both uncritical rationalism and the absence of Darwinian patterns in the traditional epistemology. $\mathrm{He}$ is especially disappointed with the situation in the philosophy of biology where before his analysis of evolutionary theory in his $\mathrm{PhD}$ Thesis, ,the literature on the subject was limited, and much of it was very bad" ${ }^{10}$. Similar wording suggests that Ruse would not accept a trivial interpretation of his new meta- scientific patterns since he announces radical revisions in the traditional theory of knowledge.

There seems to exist a model in which one might accept the two sociobiological

7 TD, 162.

${ }^{8}$ M. Ruse, Darwinism and Determinism, Zygon, 22 (1987) 423.

${ }^{9}$ A. Zahavi, Mate selection - a selection for a handicap, J. Theor. Biol., 53 (1975) 205.

Cf. R. Dawkins, The Selfish Gene, Oxford University Press: London 1976, $171 \mathrm{f}$.

${ }^{10}$ Introduction, 5. 
assumptions mentioned above as well as the traditional version of the metascientific rationalism. I will call such an interpretative proposal the correspondence model. The term „correspondence” indicates that one must not introduce mutual opposition between the objective content of scientific theories and the biological basis of the thinking subject on the one hand, and the truth and evolutionary advantages on the other. It is, at least theoretically, possible that these three factors remain autonomous and consistent. It means that the content of scientific theories could be neither reduced to biological determinants nor explained by selective advantages despite the harmonious coexistence, respectively, of the biological, intellectual and evolutionary elements.

It is true that such a three-level correspondence seems close to a science-fiction epistemology in which biology itself generates truth which, like a good sheriff in an unsophisticated movie, always wins in the struggle for survival. Similar objections are, nonetheless, aesthetic in nature; the domain of artificial intelligence and the competition between computer programs provides at the same time an interesting example which could be useful in illustrating the basic epistemological tenets adopted in such a model that has been consistent with tenets of moderate sociobiology.

The information contained in computer software has its electromagnetic basis in the appropriate hardware. In a sense the content of software is held on the leash by hardware, since primitive or wrecked computer models could impede operating complicated and/or sophisticated programs. When approaching the situation statistically, one could argue also that market successes of particular companies depend on the objective value of their products. If Word Perfect wins in competition with Microsoft, it is probably due to its objective superiority defined in terms of utility for the average user. Neither trade competition nor the electromagnetic basis of computer software determines, however, the objective value of the output information content.

The truth of logical relations encoded in the software enters into a complex network of relationships dealing with both physical processes and market rules of competition. It would be, however, naive to argue that the content of software is entirely generated by electromagnetic impulses or could be explained by the very analysis of the competitive struggle for existence between various technological companies. Quite the contrary, experts in computer science regard as a commonplace the proposition asserting that ,electronics is almost totally irrelevant to the nature of artificial intelligence" ${ }^{\prime 1}$. Only a few general properties are required in computer mechanisms to obtain a system capable of effective information processing. After providing such basic features as a set of internal states, which makes possible elementary operations, as well as a symbolic memory accessible to the operations of writing, reading and addressing, technological details do not affect substantive results that depend on the logical structure of software. These results cannot be regarded as

${ }^{11}$ A. Newell, Artificial Intelligence and the Concept of Mind, [in:] Computers Models of Thought and Language, W. H. Freeman and Co.: San Francisco 1973, 45. 
products of the hardware basis and the content of software instructions cannot be regarded as a reality constituted exclusively by electromagnetic impulses in the technology involved.

The example provided indicates that, without questioning the traditional metascientific rationalism, one could adopt the basic epistemological tenets of moderate sociobiology together with the thesis of the mutual correspondence between biological, rational, and evolutionary factors. This correspondence model would allow us to defend the notion of objective truth because the relationships between the heterogeneous elements in question would be truth preserving; one cannot, however, attempt to consider the objective content of scientific theories as a product either of genetic determinants or of evolutionary needs. Such a strong reduction, implying arbitrary ontological monism, would remain clearly inconsistent with the facts wellknown from the field of artificial intelligence, and will possess no independent confirmations as well.

In contradistinction to the suggested model, in classical texts of radical sociobiologists we find strong statements suggesting that the objective content of scientific theories, religious beliefs and moral principles can be entirely explained by analysis of their biological basis. Articulating this version of reductionism, E. Wilson categorically insists in his classical work that ,the possibility of explaining traditional religion by the mechanistic models of evolutionary biology ... will be crucial. If religion, including the dogmatic secular ideologies, can be ... explained as a product of the brain's evolution, its power as an external source of morality will be gone forever..."12. If the computer scientists argued in the same manner, they would plainly explain the nature of computer software by arguing: „If the information processing is explained in terms of hardware's mechanisms, the content and results of the programme would be completely unessential and their informative power will be gone forever".

The same biological reductionism appears in Wilson's explanations of the content of moral principles when he argues: ,if termites had somehow managed to ascend ... to the pinnacle that human beings now occupy, ... we would find them rationally explaining an ethical system with myths, legends, sacred literature, and a termite God profoundly different from our own. Their theologians would advance, as absolute moral guidelines, a sacred caste system, cannibalism glorified, personal reproduction a sin in the worker castes, territorial war proper, darkness preferred to light..." ${ }^{13}$. In the context of this prophecy, Wilson mentions Robert Nozick's defence of the rationality of science presented in his book Philosophical Explanation. Nozick suggests there a possibility of the existence of certain objective relations and principles that human beings are tracking by biological and, in particular, genetic means. Nozick's interpretation remains consistent with the examples from the field

12 E. O. Wilson, On Human Nature, Harvard University Press: London 1978, 201.

${ }^{13}$ Conversations at Nobel XVIII, [in:] Darwin's Legacy, ed. C. L. Hamrum, Harper \& Row: San Francisco 1983, 118. 
of artificial intelligence provided above and accentuates as well the impossibility of reducing the content of human knowledge to purely biological factors. Wilson reacts to this interpretation with his usual rhetoric. He answers charmingly: „If that much is true, we have a basis for extrabiological origins of moral reasoning. But I am not sure the termites would agree" 1414

The theory of knowledge developed from the termites' point of view by the famous insect specialist finds a consistent extension in Ruse's evolutionary epistemology. The author of The Darwinian Revolution accentuates the role of illusions underlying scientific activity and provides examples of the naive and uncritical belief in reason. In his comments Ruse avoids, however, biological reductionism and introduces important distinctions when determining the criterion of truth of particular theories. In his metaphorical language, ,science is attached to biology" because ,it has its feet in Darwinian forces. But its head reaches up into non-adaptive clouds, as we push our enquiries further and further" 15

Within this framework, basic scientific principles depend on a „mind- injected element" determined by our genotype. These principles are, however, used by human beings to develop sophisticated scientific theories. Their content remains related to evolutionary goals of our species; nonetheless, it cannot be regarded as an effect of necessary genetic determinants. Consistently, in sociobiological epistemology one cannot reduce the content of scientific theories to the functions of our genes, but one must distinguish the diverse epistemological statuses of particular theories. All theories and theorems are biology-laden, but their informative value differs substantially, being dependent on many extra- genetic factors. To determine these differences precisely, one must raise the problem of the relationship between scientific realism and the sociobiological theory of knowledge.

\section{MYTHOLOGY AND REALISM IN THE THEORY OF KNOWLEDGE}

According to the classical explanation proposed by Wilson, any form of knowledge expresses a mythopoietic drive of humankind and, consequently, contains a version of scientific mythology where the term „myth" is understood in a nonpejorative sense. The so-called scientific materialism, based on the principles of sociobiology, ,is accepted as the more powerful mythology" because it ,is the only mythology that can manufacture great goals from the sustained pursuit of pure knowledge" ${ }^{16}$. In the adopted terminological convention, mythopoietic components of knowledge do not exclude the possibility of accepting the standpoint of cognitive realism. Evolutionary epics intermingle with the realistic description of physical facts in what is called by Ruse „common- sense realism” " ${ }^{17}$. Determining the exact content of this epistemological standpoint seems scarcely possible because Ruse states his clear opposition to the scholastic and Popperian practice of introducing precise

\footnotetext{
${ }^{14}$ Ibid., 119.

$15 \mathrm{TD}, 175$.

${ }^{16}$ E. O. Wilson, On Human Nature, 207.

17 TD, 191.
} 
definitions and minute divisions ${ }^{18}$. Consequently, he resticts himself to repeating the Quinean dictum that science is nothing but self-conscious common sense, and formulates later a rather cautious opinion that chairs, tables, and trees exist in reality, and are not chimeras like Macbeth's dagger ${ }^{19}$. He is inclined to recognize also the existence of electrons, genes, and dinosaurs; the importance of his ontological commitment is, however, lessened by the fact that it is only our biological propensity which „provides us with our criteria of truth and reason” ${ }^{20}$. Consequently, „it is difficult to know, in human terms, precisely what nature a thing-in-itself would possess" ${ }^{21}$ since our commitment to a particular ontology is nothing but a consequence of interaction between epigenetic rules and biological environments. The role of biologically conditioned epigenetic rules is such that ,we should not be surprised when this latter [i.e. a person-independent - J. Z.] reality collapses into paradox and non-being" 22 .

Such a general description of epistemological tenets can be consistent with such remote cognitive standpoints as critical realism and van Fraassen's constructive empiricism. On the one hand, we find in Rusean epistemology noncontroversial statements that "human thought is moulded and constrained by the epigenetic rules" 23. On the other, the rational accomplishment of mankind seems to be called into question by him when he declares that ,vanity and ignorance alone support the claim that human reason has a privileged status" ${ }^{24}$. Whatever the „privileged status" means, the importance of the latter statements is immediately softened by the concession that our intellectual achievement has ,, a meaning of its own, transcending biology” 25 .

The large spectrum of esentially different statements allows Ruse to reconcile his sociobiological theory of knowledge with substantially different epistemological stances. To counteract this semantic fuzziness and to determine the exact content of the Rusean version of the common-sense epistemological realism, we can focus on his interpretation of mathematics. In this discipline the vague terms of mythological components and evolutionary advantages imply consequences that are particularly easy subjects for critical appraisal. The imprecise declarations about explanatory myths and the intellectual struggle for survival take on a new meaning when we confront them with the reality of mathematical knowledge. Mathematics, regarded both as a most original achievement of the human mind and as our non-observable culture, can be especially useful in answering the question what role is played in sociobiological epistemology by the objective content of our knowledge.

\section{EVOLUTIONARY METAMATHEMATICS}

${ }^{18} \mathrm{TD}, 192$.
$19 \mathrm{TD}, 192$.
${ }^{20} \mathrm{TD}, 192$.
${ }^{21} \mathrm{TD}, 194$
${ }^{22} \mathrm{TD}, 196$.
${ }^{23} \mathrm{TD}, 206$.
${ }^{24} \mathrm{TD}, 206$.
${ }^{25} \mathrm{TD}, 206$. 
Admitting that he cannot offer a fully developed philosophy of mathematics, Ruse specifically denies the traditional conception of objective mathematical truths and maintains that the apparent objectivity of mathematics is illusory ${ }^{26}$. The essence of the so-called Darwinian approach to mathematics is to be expressed in the thesis that human individuals themselves objectify the truths of logic and mathematics, because personal certainty gives us a selective advantage in our struggle for existence.

Probably nobody would question that knowledge of mathematics and logic is really useful for our species. Selective advantages, however, can result from knowing not only elementary arithmetic, but also trivial facts dealing with prosaic realities of everyday life. The question arises then: Is our knowledge useful because it is true, or rather is it regarded as true because it appears useful in the struggle for survival? The fact of the evolutionary utility of a subjective belief in the truth of certain statements scarcely provides an ultimate criterion of truth. Subjective conviction of the certainty of mathematics may have evolutionary usefulness, but an analogous psychological feeling of certainty can be generated by ideological dogmas or pseudo-scientific speculations. A sociobiological philosophy of mathematics does not explain what difference there is between the objective certainty of mathematical theorems and the subjective certainty of supporters of Nazi anthropology or Lysenko's biology. It does not explain why in elementary arithmetic we have no mathematical Lysenko's who, preserving the standard meaning of the employed terms, would argue that ' $2+2=5$ '. Such nonstandard arithmetic would certainly provide evolutionary advantages for particular groups demonstrating their territorial or financial supremacy in the struggle for existence. If Lysenkos appear in biology rather than in mathematics, it seems to suggest that the very essence of mathematical knowledge differs from the essence of biological sciences. Neither Ruse nor any of his collaborators explains what constitutes the essence of this difference.

In the same style Ruse ignores the question as to what evolutionary advantages result from particular mathematical discoveries. One may provide many examples that led to immediate disadvantages and existential troubles. It would be enough to mention here the drama of Georg Cantor. His theory of infinite sets provoked a radical opposition of the institutional science represented by Leopold Kronecker. The conflict resulted in Cantor's psychic breakdown, severe depression and death in a mental hospital. His intellectual legacy was recognized in a short time by authors who, together with David Hilbert, did not want to leave the new "mathematical paradise” discovered by Cantor. The discoverer himself, however, except for an intellectual advantage, gained no other evolutionary advantages. Contrary to sociobiological principles, important intellectual achievements yielded the definitive defeat in his struggle for survival.

Ruse himself distinguishes the different statuses of various mathematical theorems. He seems to combine sociobiology and intuitionism when he argues that there is a set of epigenetically determined simple mathematical principles and rules which appear to our consciousness as self-evident. In another context he seems to

$26 \mathrm{TD}, 173$. 
express his support for modified metamathematical formalism, when he argues that after adopting the elementary set of genetically determined truths, logicians and mathematicians demonstrate their creative fantasy in developing new systems of fantastic games. More advanced mathematics is just ,an epiphenomenon on a biologically based set of simple statements and rules" 27 .

This approach reminds one of Kronecker's thesis that the integers were made by God, and everything else is the work of man. One difference is that in Ruse's philosophy God is replaced by epigenetic rules; another - that nobody knows which mathematical axioms are determined by these rules. The optimistic faith that it is enough to have a set of ,simple statements and rules" to construct the whole body of mathematics turned out to be definitely too optimistic when, at the beginning of our century, basic divergences of opinions emerged in the quest for fundamental axioms to which mathematics was supposed to be reduced.

Without paying any special attention to metamathematical discoveries of our century, Ruse tries to apply his scheme to explain the genesis of non-Euclidean geometries. He suggests that the Euclidean fifth postulate, though suspect, remained unquestioned till the 19th century because it was relatively unimportant in the evolutionary struggle for existence. When taking part in this struggle, our Australopicine ancestors had to „know that a straight line is the quickest way from A to B. But who cares about whether or not parallel lines never meet?" ${ }^{2 s}$. One may doubt whether or not the concept of parallel lines was indeed pragmatically useless for primitive societies but consistently one should ask why these societies were so interested in theoretical problems that deal, for instance, with the equality of all right angles. The fourth Euclidean postulates asserts that all right angles are equal to one another, and this postulate aroused no objections though its pragmatic utility seems rather dubious and Australopicine rather should not be disturbed with its content.

Perhaps sociobiology may be used to explain the genesis of certain concepts in pre-Euclidean mathematics. Euclids' Elements with its basic notions of indivisible points, breadthless lines and infinite surfaces remain, however, as distant from evolutionary adaptive advantages as Wilson's evolutionary epistemology is distant from contemporary mathematics. The most important questions that attract the attention of successors of Hilbert and Godel are in this epistemology either ignored or left with metaphorical maxims. Ruse's epistemological comments on significance of Godel's incompleteness theorem may well illustrate this procedure. In clear inconsistency with Ruse's philosophy of mathematics, this theorem can be regarded neither as intuitively self-evident nor as an arbitrary convention. It is not self-evident because its discovery was a shock for logicians. Equally it is not a convention resulting from a creative play with symbols, because there exists no mathematical game in which our creativity could be expressed in defining a system which is simultaneously: 1) isomorphic with the Principia Mathematica, 2) consistent, 3) complete.

That fact of the incompleteness of arithmetic, regardless of its possible

27 TD, 170. 
significance for our evolutionary development, appears as independent of both our conventions and our intuitions; the notion of mathematical objectivity is especially conspicuous when we consider the amazing results of Godel's discovery. When many argue that this discovery belongs to the greatest discoveries of humankind and the questions inspired by them ,are pregnant with possibilities and fraught with dangers” 28. Ruse in his sociobiological epistemology merely notices that „worries about failures in completeness are vestiges of Platonic/theistic thinking" ${ }^{29}$. This approach illustrates the well-known method in which difficult questions are avoided and replaced by the distribution of philosophical labels. The content of the disturbing theorem provides, nevertheless, an especially suggestive counterexample to the sociobiological philosophy of mathematics. Incompleteness of a logical system appears as an objective counterintuitive fact irrelevant for biological selection. The easiest procedure to eliminate questions of the objective nature of this incompleteness is to impute Platonic or religious influence to philosophical opponents.

Vague metaphors in which one ignores long debates in the foundations of mathematics may appear attractive for epistemological radicals searching after simple explanations of the nature of mathematics. The simplicity of their image of mathematics results, unfortunately, from the systematic ignoring of basic discoveries of our century that revealed essential flaws in simple metamathematical schemes. One cannot effectively eliminate these flaws by introducing ambiguous terms to define relations of primary importance. Their ambiguousness results in interpretive arbitrariness. For instance, Wilson's statements about the genetic leash can be reconciled with mutually inconsistent standpoints in the philosophy of mathematics. An attempt to interpret mathematics as an evolutionarily useful illusion ends in semantic chaos, as well as in producing new interpretive illusions shared on a metamathematical level.

\section{EVOLUTIONARY ADVANTAGES AND INTERPRETIVE TROUBLES}

In certain respects the sociobiological theory of knowledge seems to resemble the famous philosophy of Panglossianism ridiculed by Voltaire in his critique of Leibniz. The Leibnizian Doctor Pangloss cultivated the strong conviction that we live in the best of the possible worlds. Unfortunately, except his subjective optimism, he had no other arguments to justify his views. In sociobiological epistemology one possesses no arguments that the evolutionary interest of genes constitutes the most important criterion of truth. The thesis is adopted axiomatically to obtain a simple philosophy in which former epistemological debates are instantaneously dissolved.

In the same manner sociobiology dissolves several problems that are elementary for contemporary science and its philosophy. Conjectural perhapses are adopted as

$28 \mathrm{TD}, 171$.

${ }^{29}$ S. G. Shanker, Preface to Godel's Theorem in Focus, (London-New York 1988), p. vii.

${ }^{30} \mathrm{TD}, 170$ note 4. 
unquestionable axioms to find an instant solution to the most complicated questions. While certain statements imply that sociobiology conclusively disclosed the ultimate biological roots of mathematics, other announcements are much modest in style, and only suggest that the epigenetic rules ,probably play a key role when we think mathematically" ${ }^{\prime 2}$. This cautious opinion, as its only justification, has a commonsense remark suggesting that ,innately, we think in terms of symbol and quantity because such a way of thought proved its adaptive worth" 32 .

The common-sense mathematics regarded as $a$ mixture of quantities and symbols has its intellectual counterpart in naive anthropomorphic physics in which important substantive issues are approached only in their accidental aspects. Many puzzling and controversial problems of modern physics appear in this framework as interpretive conventions adopted exclusively for pragmatic reasons. For instance, the Heisenberg's uncertainty principle, is presented as a pragmatic device introduced merely to bar ,the asking of awkward ... questions" ${ }^{\text {"33 }}$. Electrons turn out to be for Ruse simply "funny entities... which (apparently) have contradictory properties" 34 .

One can, certainly, develop such an approach for the same reason as one can interpret the history of mankind by collecting anecdotes and jokes. A dangerous illusion would arise, however, if one thinks that his collection of entertaining gags may be treated on an equal footing with scientific analysis because our sense of humor is also biologically conditioned and evolutionarily useful.

\section{ORWELLIAN SOCIETIES AND RUSE'S EPISTEMOLOGY}

Epistemological principles proposed by Ruse and Wilson remain noncontroversial when applied to the early hominids for whom theoretical knowledge really facilitated their struggle for existence. The same principles result however in grotesque effects if one tries to use them in order to explain the rise of the nonEuclidean geometries or quantum mechanics. The Rusean axiom of the illusory nature of scientific objectivity ${ }^{35}$ ultimately implies a denial of the correspondence model proposed in the initial part of this paper. Biological, intellectual and evolutionary factors cannot be regarded as mutually irreducible elements of the process of cognition because the intellectual mixture of necessary facts and epical myths is both genetically determined and subordinate to the criterion of evolutionary advantages. Consequently, evolutionary advantage seems to constitute the ultimate criterion of truth, while the mythopoietic component of our theories varies together with the variation of environmental conditions.

The thesis declaring the utility of knowledge in the evolutionary struggle for survival was formulated in the context of the actually known biological realities of the struggle in question. Let us develop a Gedanken-Experiment in which the

\footnotetext{
${ }^{31}$ M. Ruse, Darwinism and determinism, 423.

32. Ibid., 423.

33 TD, 157.

34 TD, 154.

35 TD, 173.
} 
terrestrial conditions of evolution are radically different due to invasion of extraterrestrial humanoids representing a technologically dominant civilization. These humanoids, let us call them humanoids B, were expelled from Andromeda where they were defeated in their struggle for survival by humanoids A who accept a counterpart of Aristotelian logic and our ethics of altruism. Humanoids B propagate an aggression-laden ethics of evolutionary class struggle. Their logic, let us call it dialectical logic, contains as a basic axiom the principle of contradiction asserting that A and non A may be simultaneously accepted for pragmatic reasons. In their social philosophy these creatures proclaim a future classless and truthless society in which all leading roles would be played by the humanoids B who would be simply the most equal members in the future society of equal beings. The content of their theories does not seem especially eccentric when one calls into question the principles formulated by termite intellectuals in the Wilsonian analogy described above. In this invented story of the Orwellian humanoids I use the same interpretative means that are systematically used by Wilson and Ruse in their arguments.

If the Orwellian situation were extended into the future of biological evolution, the humanoids B would constitute a victorious class in the terrestrial struggle for existence due to their technological supremacy dependent on discoveries unknown to the species homo sapiens. Consistently, in accordance with the Rusean principles of sociobiological epistemology, their scientific theories, ethical principles and personal convictions should be considered true since they lead to obvious advantages in the terrestrial struggle for survival. The advantages are open not only for the humanoids B themselves but also for those representatives of the human species who praise dialectical logic and enthusiastically support the program of the construction of the truthless society.

The analogy provided appears grotesque in so far as we think of the humanoids $\mathrm{B}$ in Orwellian convention regarding them as immoral propagators of totalitarian practices and of false ideology. Such an appraisal implies extrapolating our moral principles and criteria of truth and applying them to the representatives of the different species which evolved in entirely different physical and biological conditions. If, according to Ruse's contention, all knowledge is "grounded in biology" and the biological structure of the humanoids' DNA (if any) differs from ours, it is possible that their logic, axiology, ethics, and social philosophy are also radically different from ours. Since these technologically superior humanoids won the struggle for survival with the human species, their theoretical interpretation of the world must be regarded as evo 
lutionary advantageous and true as well. Ethics of intellectual slavery and conformism would be in such a situation the highest evolutionary achievement of the homo sapiens.

I do not think this story to provide a counterexample to the generally understood sociobiological theory of knowledge. It discloses only inconsistencies contained in Ruse's version of sociobiological epistemology. These inconsistencies result from the cavalier ingnoring of rational and critical metascientific analyses of the past. An attempt to replace them by vague metaphors and rhetorical ruses could satisfy only those authors who prefer visionary declarations to substantiated arguments. One must then definitely both de-ruse and de-Ruse the sociobiological theory of knowledge to determine how rational content and biological- evolutionary determinants coexist in our knowledge. 